\title{
Sistemas de informação para a COVID-19
}

\author{
Maíra Lima de Souza \\ Maria Yury Travassos Ichihara ${ }^{2}$ \\ Samila Oliveira Lima Sena ${ }^{3}$
}

1 Doutoranda pelo doutorado Multiinstitucional e Multidisciplinar em Difusão do Conhecimento pelo Instituto Federal de Educação, Ciência e Tecnologia da Bahia (IFBA). Atua na Curadoria Digital do Centro para Integração de Dados e Conhecimentos para Saúde (Cidacs) da Fundação Oswaldo Cruz (Fiocruz).. Interessada em modelagem de dados para vigilância epidemiológica em arboviroses e gestão de dados.

2 Médica, doutora em Saúde Pública, professora colaboradora no Instituto de Saúde Coletiva (ISC) da Universidade Federal da Bahia (UFBA), vice-coordenadora do Centro para Integração de Dados e Conhecimentos para Saúde (Cidacs). Atua em avaliação de determinantes e de políticas sociais usando grande volume de dados.

3 Mestra em Matemática com concentração em Estatística e graduada em Estatística pela Universidade Federal da Bahia (UFBA). Atua como coordenadora do Núcleo de Produção de Dados do Centro para Integração de Dados e Conhecimentos para Saúde (Cidacs) da Fundação Oswaldo Cruz (Fiocruz).

SOUZA, M. L. de; ICHIHARA, M. Y. T.; SENA, S. O. L. Sistemas de informação para a COVID-19 In: BARRETO, M. L.; PINTO JUNIOR, E. P.; ARAGÃO, E.; BARRAL-NETTO, M. (org.). Construção de conhecimento no curso da pandemia de COVID-19: aspectos biomédicos, clínicoassistenciais, epidemiológicos e sociais. Salvador: Edufba, 2020. v. 2. DOI: https://doi.org/10.9771/9786556300757.003 


\section{Introdução}

O cumprimento das funções de vigilância epidemiológica depende da disponibilidade de dados que sirvam para subsidiar o processo de produção de informação para ação. A qualidade da informação produzida depende, assim, de uma adequada coleta de dados e de um sistema de notificação que proporcione dados confiáveis acerca do comportamento das doenças.

Coletados em todos os níveis de atuação do sistema de saúde, é no local de ocorrência do evento sanitário que os dados devem ser primariamente tratados e estruturados para se constituírem em informação. Por serem estratégicas, é de responsabilidade das instituições geradoras garantir que tanto a forma quanto o conteúdo das informações produzidas sejam adequados a compreensão da epidemia, seus riscos e impactos. O fato é que à medida que há um amadurecimento do processo e informações mais detalhadas se tornam disponíveis, a organização e análise de informação tendem a se tornarem mais acuradas.

A exemplo do que ocorreu em países europeus e asiáticos, o controle da pandemia de COVID-19 no Brasil dependeu de uma vigilância epidemiológica estruturada. Quando o Ministério da Saúde decretou a transmissão 
comunitária da doença em todo o território nacional, em 20 de março de 2020, estava em vigor a estrutura de vigilância das síndromes respiratórias. Ainda que o sistema nacional de vigilância epidemiológica contasse com agentes de vigilância nos níveis estadual e municipal, com um programa de vigilância sentinela específico para influenza, com uma rede de laboratórios e uma Rede Nacional de Alerta e Resposta às Emergências em Saúde (Rede CIEVS) (BRASIL, 2003), além do próprio Centro de Informações Estratégicas em Vigilância em Saúde (CIEVS), para dar conta da circulação simultânea do novo coronavírus (SARS-CoV-2), do influenza e de outros vírus respiratórios no âmbito da Emergência de Saúde Pública de Importância Nacional (Espin), este sistema precisou ser adaptado. (BRASIL, 2020c)

Em síntese, sistematizar a informação para um agravo requer tratar dos aspectos da coleta dos dados e dos critérios de definição, notificação e investigação de caso para a identificação dos indivíduos que apresentam o agravo de interesse para o monitoramento das condições de saúde.

Assim, este capítulo versará sobre o sistema de informação para a COVID-19 e seu processo de estruturação até a realidade que conhecemos hoje. Abordaremos os pontos a seguir: (i) histórico de controle e vigilância de síndromes gripais; (ii) a evolução do registro de notificação de COVID-19 como emergência de saúde pública; (iii) notificação e os sistemas de informação utilizados para monitoramento de casos da COVID-19: e-SUS Ve, GAL e SivepGripe. Os ajustes necessários para adequar esses sistemas para o registro das notificações da COVID-19. A ficha de notificação e os dados coletados; (iv) os dados: a experiência da notificação a partir dos dados do Estado e Município; e (v) considerações finais. 


\section{Histórico de controle e vigilância de síndromes gripais}

O potencial de alguns vírus respiratórios em causar epidemias e/ ou pandemias ante a sua alta taxa de transmissibilidade e o seu impacto nas morbidades e mortalidades tem mobilizado uma constante revisão e atualização de procedimentos e aspectos de vigilância.

O processo de amadurecimento do país frente a vigilância das doenças gripais perpassa tanto pelo processo de incorporação do Regulamento Sanitário Internacional (RSI), em 2005 (LIMA; COSTA, 2015) no ordenamento jurídico-administrativo brasileiro quanto pela resposta nacional aos surtos gripais, principalmente aos que ocorreram no século XXI: a epidemia de gripe aviária (A(H5N1)), ocorrida entre os anos 2003 e 2004, e a pandemia de 2009, pelo vírus influenza A(H1N1)pdm09. (BRASIL, 2010a, 2010b)

Cabe ao Estado, entre outras competências, garantir a segurança sanitária quando em Espin para não se tornarem Emergências de Saúde Pública de Importância Internacional (Espii). O processo de internalização das regulamentações sanitárias, que ocorre por meio de decretos legislativos, resultou, dentre outros produtos, na declaração de Espin e instituição da Força Nacional do Sistema Único de Saúde (FN-SUS) (BRASIL, 2006); na definição das terminologias adotadas em legislação nacional (BRASIL, 2011b); e na escolha da Secretaria de Vigilância em Saúde (SVS) como Ponto Focal nacional junto à Organização Mundial de Saúde (OMS) e como gestora do Sistema Nacional de Vigilância em Saúde, que abrange a vigilância epidemiológica, a vigilância ambiental em saúde - incluindo ambiente de trabalho -, o Sistema Nacional de Laboratórios de Saúde Pública - nos aspectos pertinentes à vigilância epidemiológica e ambiental em saúde -, os sistemas de 
Informação Epidemiológica e o Programa Nacional de Imunização (BRASIL, 2006; LIMA; COSTA, 2015)

A implantação de um Sistema de Vigilância Epidemiológica da Influenza em âmbito nacional iniciou em 2000. Nesse período, focos IA (gripe aviária) de alta patogenicidade ocorriam no mundo. Uma vigilância passiva foi estabelecida com base nas redes de unidades de saúde sentinela e de laboratórios e incluía também a vigilância de Síndrome Gripal (SG). O principal objetivo dessa vigilância era a identificação dos vírus respiratórios em circulação no país, além do monitoramento da demanda de atendimentos por SG, a partir dos dados obtidos pelo Sistema de Informação da Vigilância Epidemiológica da Gripe (Sivep-Gripe). (BRASIL,2010a, 2010b)

Após a pandemia pelo vírus A(H1N1)pdm09, em 2009, a vigilância epidemiológica da influenza se reorganizou. Houve investimento nas ações de vigilância para a rápida detecção de casos suspeitos a partir da rede instalada de vigilância de influenza com agilização dos fluxos de envio de amostras e liberação dos resultados laboratoriais. Foi estabelecido um Protocolo de Notificação e Investigação Imediata e criado aplicativo on-line do Sistema de Informação de Agravos de Notificação (Sinan) para otimizar as notificações. Houve, também, intensificação das medidas sanitárias em portos, aeroportos e fronteiras, assim como recomendações de alerta aos viajantes. (COSTA, 2015; TEMPORÃO, 2009)

Com essa mudança, a Síndrome Respiratória Aguda Grave (SRAG) de casos hospitalizados e os óbitos relacionados à influenza passaram a ser notificados no Sinan Influenza Web. O processo de reorganização e fortalecimento, iniciado anos antes e ampliado em 2011 com as Portarias n ${ }^{\circ}$ 2.693/2011-2012 e n ${ }^{\circ}$ 183/2014, culminou com a formação da Rede Sentinela em influenza composta por Unidades de Saúde de Municípios, Estados e do Distrito Federal, 
a partir das suas respectivas Secretarias de Saúde. (BRASIL, 2010a, 2010b; COSTA, 2015; ROSSETTO; LUNA, 2016)

Realizada nos serviços de saúde sob a égide da demanda espontânea, a vigilância sentinela da influenza possui dois componentes: vigilância de SRAG (em unidade de terapia intensiva) e vigilância de SG (a partir de pronto-atendimento, emergência e ambulatório). (BRASIL, 2014)

Como o principal objetivo da vigilância é o monitoramento periódico e sistemático com vistas a detecção precoce de cenários epidêmicos e/ou surtos, o trabalho se concentra tanto em período não epidêmico e quanto em cenário de surtos. Envolve as seguintes atividades, que devem ser desenvolvidas durante todo o ano (BRASIL, 2010b, 2015):

a. A unidade sentinela deve realizar o registro individual de casos de SG. Isso envolve tanto a coleta de amostra quanto o preenchimento de ficha individual do paciente do Sivep-Gripe e encaminhar ao laboratório juntamente com a amostra;

b. Realizar monitoramento viral, conforme rotina estabelecida pela vigilância epidemiológica municipal/estadual e pelo Laboratório Central de Saúde Pública (Lacen).

c. Quando da suspeição de casos na comunidade, notificar imediatamente o número de casos suspeitos para a vigilância da Secretaria Municipal de Saúde (SMS) e/ou Secretaria Estadual de Saúde (SES), ou à SVS / Ministério da Saúde (MS);

d. A notificação imediata deve ser por meio da Ficha de Investigação Individual;

e. A vigilância epidemiológica da SMS deverá notificar imediatamente à SES e esta à SVS/MS, por meio do Sinan Influenza on-line e informar ao hospital sobre o encaminhamento do paciente e seguir o fluxo estabelecido pela SMS/SES, de acordo com o Protocolo de Manejo Clínico de SRAG. 


\section{A evolução do registro de notificação de GOVID-19 como emergência de Saúde Pública}

A resposta nacional em face da pandemia do novo SARS-CoV-2 seguiu o disposto no Plano nacional de resposta à emergência em saúde pública (2014). Em 22 de janeiro de 2020, foi ativado o Centro de Operações de Emergências em Saúde Pública. À época, aproveitou-se da estrutura de vigilância e dos sistemas de monitoramento do influenza e do $\mathrm{H} 1 \mathrm{~N} 1$, bem como dos seus protocolos e planos de resposta (BOLETIM EPIDEMIOLÓGICO INFECÇÃO HUMANA PELO NOVO CORONAVÍRUS, 2020a); contudo, havia a necessidade de estabelecer protocolos e procedimentos específicos e um adequado plano de contingência, bem como a necessidade de criar rapidamente um sistema de registro das notificações específico para COVID-19 seguindo os procedimentos do Regulamento Sanitário Internacional.

Todas as ações foram coordenadas pela SVS/MS em cooperação com os Estados, Distrito Federal e Municípios. (BRASIL, 2014) E todas as informações de caso passaram a ser reunidas e monitoradas pelo Centro de Informações de Estratégias e Respostas em Vigilância em Saúde (Cievs); pelas unidades e equipes de monitoramento dispostas nos estados e nas secretarias de saúde municipais, que em conjunto formam a Rede Nacional de Alerta e Resposta às Emergências em Saúde Pública (Rede Cievs), e pelas secretarias de atenção à saúde. (BRASIL, 2014; CARMO; PENNA; OLIVEIRA, 2008)

Fora estabelecido que os casos, inclusive, os casos de óbitos, deveriam ter notificação imediata e que a comunicação deveria ser feita por e-mail, ${ }^{4}$ telefone (local ou nacional) e através do preenchimento da ficha de notificação FormSUS-cap 2019-nCoV.

4 E-notifica/notifica@saude.gov.br. 
(BOLETIM EPIDEMIOLÓGICO INFECÇÃO HUMANA PELO NOVO CORONAVÍRUS, 2020a)

O FormSUS-cap 2019-nCoVO, designado como instrumento oficial de coleta e caracterização de casos, versão adaptada do formulário FormSUSCap, implantado em 2019, seguiu o padrão recomendado pela OMS. Ele foi elaborado com o intuito de coletar dados a partir de um conjunto de sinais e sintomas de maneira que os países pudessem compartilhar informações padronizadas no âmbito do Regulamento Sanitário Internacional. (BOLETIM EPIDEMIOLÓGICO INFECÇÃO HUMANA PELO NOVO CORONAVÍRUS, 2020a; WHO, 2020) Dessa forma, o formulário coletava informações relacionadas ao paciente, informações clínicas, informações de exposição e viagem nos 14 dias anteriores ao início dos sintomas - antes de relatar se assintomático - e informações laboratoriais. ${ }^{5} \mathrm{O}$ código para registro de casos, conforme as definições, passou a ser o B34.2 (CID10) - Infecção por coronavírus de localização não especificada -, e os códigos utilizados como marcadores da pandemia no Brasil, definidos pela OMS, para a identificação ou não do vírus são: U07.1 (COVID-19, vírus identificado) e U07.2 (COVID-19, vírus não identificado, clínico-epidemiológico). (BOLETIM EPIDEMIOLÓGICO INFECÇÃO HUMANA PELO NOVO CORONAVÍRUS, 2020a) Na mesma linha em que for alocado o B34.2 (Infecção pelo coronavírus de localização não especificada), deve constar, também, o código marcador U07.1 ou U07.2. (BRASIL, 2020c)

5 A OMS deve ser informada de maneira oportuna, precisa e em nível suficiente de detalhamento sobre definições de caso, resultados laboratoriais, fonte e tipo de risco, número de casos e de óbitos, condições que afetam a propagação da doença; e as medidas de saúde empregadas, informando, quando necessário, as dificuldades confrontadas e o apoio necessário para responder à possível Espii. Veja mais em: https://portalarquivos.saude.gov.br/images/pdf/2020/April/03/BE6Boletim-Especial-do-COE.pdf. 
Assim, a solução do FormSUS-cap 2019-nCoV estabelecia-se como o principal instrumento para coletar dados de forma padronizada no âmbito nacional. Dados desse formulário eram submetidos automaticamente ao MS e posteriormente validados pela Diretoria da Vigilância Epidemiológica (DIVE). Contudo, não se tratava de um sistema de informação. ${ }^{6}$

O aumento do número de notificações tornou insuficiente a gestão de dados pelo FormSUS/RedCap, uma vez que os estados não conseguiam acessar as informações nominais notificadas no novo sistema, resultando no acúmulo de casos sem que fosse possível a visualização. (BAHIA, 2020b) Como alternativa, o Departamento de Informática do Sistema Único de Saúde (DATASUS) instituiu o e-SUS VE (e-SUS Vigilância Epidemiológica) como instrumento de gestão de dados on-line, de modo que cada nível de gestão do sistema - unidade de saúde, município, estado - pudesse gerenciar os dados de sua área de abrangência e o MS pudesse visualizar e garantir que os números fossem os mesmos e tivessem integridade e segurança entre a informação do notificador e da vigilância. (BOLETIM EPIDEMIOLÓGICO INFECÇÃO HUMANA PELO NOVO CORONAVÍRUS, 2020b) Ficou de competência e de responsabilidade dos municípios acessar o sistema e-SUS para fechar as investigações epidemiológicas, ou seja, validar, corrigir ou descartar os casos lançados. (BAHIA, 2020c)

A transição para a nova forma de notificação dos casos suspeitos da COVID-19 iniciada em 27 de março fora constituída de três fases:

a. Fase 1: desabilitação da notificação de casos no RedCap e instituição da notificação para e-SUS VE, com incentivo ao autocadastro dos usuários. Embora a Ficha de Notificação tenha

6 Ficha RedeCap disponível em: https://www.saude.ce.gov.br/wp-content/uploads/ sites/9/2020/02/FICHA-DE-NOTIFICACAO-COVID19.pdf. 
sido simplificada, havia a necessidade da incorporação de dados antigos do RedCap para o novo sistema;

b. Fase 2: Possibilidade de importação e exportação dos dados em formato Comma-Separated-Values (CSV);

c. Fase 3: Integração do e-SUS VE com outros sistemas, inclusive a Rede Nacional de Dados para Saúde, com cruzamento de resultados no Gerenciador de Ambiente Laboratorial (GAL) e de laboratórios privados que passariam a integrar a esta rede. Deve-se ficar claro que a estrutura do sistema que comporia o sistema de informação sobre a infecção humana pelo novo coronavírus foi construído à medida que as informações e novas evidências técnicas e científicas foram publicadas, visto que a definição do fluxo operacional precisava dar conta da definição de casos suspeitos e confirmados, da classificação e encerramento de casos, da notificação e registro de casos, das legislações vigentes e da forma de investigação laboratorial.

Atualmente, a orientação do MS é que os casos de SG suspeitos da COVID-19 devem ser notificados no e-SUS VE; os casos com quadro de SRAG e óbitos de COVID-19 devem ser notificados no sistema Sivep-Gripe. (BOLETIM EPIDEMIOLÓGICO INFECÇÃO HUMANA PELO NOVO CORONAVÍRUS, 2020c) A notificação passou a ser feita nas seguintes modalidades:

a. Na Atenção Primária e nas demais unidades de saúde - clínicas, consultórios, pronto atendimento etc. -, os casos de SG devem ser notificados por meio do sistema e-SUS VE;

b. Nas Unidades de Vigilância Sentinela de Síndrome Gripal, os casos de SG devem seguir os fluxos já estabelecidos para a vigilância da influenza e outros vírus respiratórios, devendo ser notificados no Sivep-Gripe;

c. Nos hospitais, os casos de SRAG hospitalizados devem ser notificados no Sivep-Gripe; 
d. Óbitos por SRAG independente de internação devem ser notificados no Sivep-Gripe. Caso o município não possua cadastro no Sivep-Gripe, por não terem unidade hospitalar, orienta-se que o cadastro no sistema seja via o Cadastro Nacional de Estabelecimentos de Saúde (CNES) de suas vigilâncias para a correta e oportuna notificação. ${ }^{7}$

7 Com o advento da pandemia, visando dar celeridade ao processo de investigação e publicação das informações de óbitos, o MS recomendou que os registros que contiverem menção de COVID-19 dentre as causas de morte fossem cadastrados no Sistema de Informação sobre Mortalidade (SIM) com prioridade, num prazo de 48 horas. Assim, as notificação de óbitos e o preenchimento e emissão da declaração de óbito e registro no SIM seguem tanto as orientações contidas no "Manejo de corpos no contexto do novo coronavírus COVID-19" quanto das "Orientações para codificação das causas de morte no contexto da COVID-19". (BAHIA, 2020d) 
Figura 1 - Fluxo de notificação COVID-19

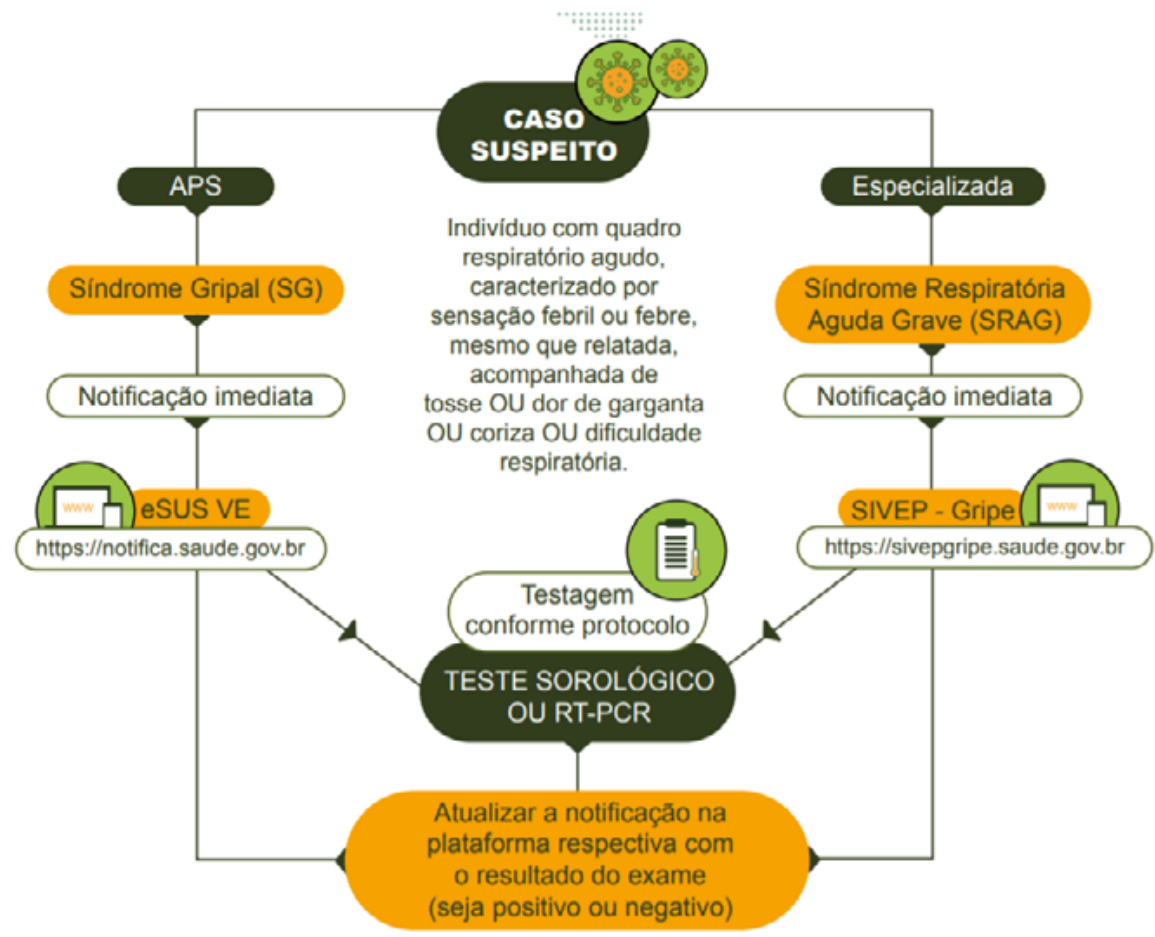

Fonte: Boletim Epidemiológico COVID-19 (2020a).

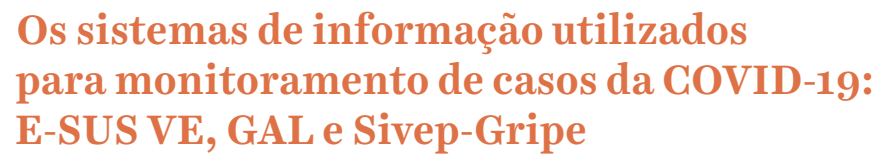

Normalmente cabe ao Sinan coletar informações sobre os agravos de importância nacional. Os indícios que o governo federal cogitou 
seu uso aparece no primeiro boletim epidemiológico lançado pelo MS, o qual diante da insuficiência de informações sobre o espectro clínico da doença e características epidemiológicas, orientou que os casos suspeitos fossem também registrados no Sinan na ficha de notificação individual. (BOLETIM EPIDEMIOLÓGICO INFECÇÃO HUMANA PELO NOVO CORONAVÍRUS, 2020a) Contudo, o fato do sistema depender da transferência de arquivos das secretarias municipais e estaduais de saúde deixa-o pouco funcional para situações que demandam atualização de dados em tempo real.

Os sistemas escolhidos para registrar as notificação de casos da COVID-19 tem como característica a atualização on-line e não demandam transferência de arquivos. Assim, o monitoramento da epidemia ocorre a partir do e-SUS VE, do Sivep-Gripe e do GAL. E do SIM para os casos de óbitos. Cada sistema possui sua própria base de dados e elas não se comunicam.

Importante salientar que a entrada dos registros e a conclusão de casos deve obedecer aos critérios de definição de caso estabelecido, conforme indica o fluxo (Figura 2). 
Figura 2 - Definições de caso de COVID-19

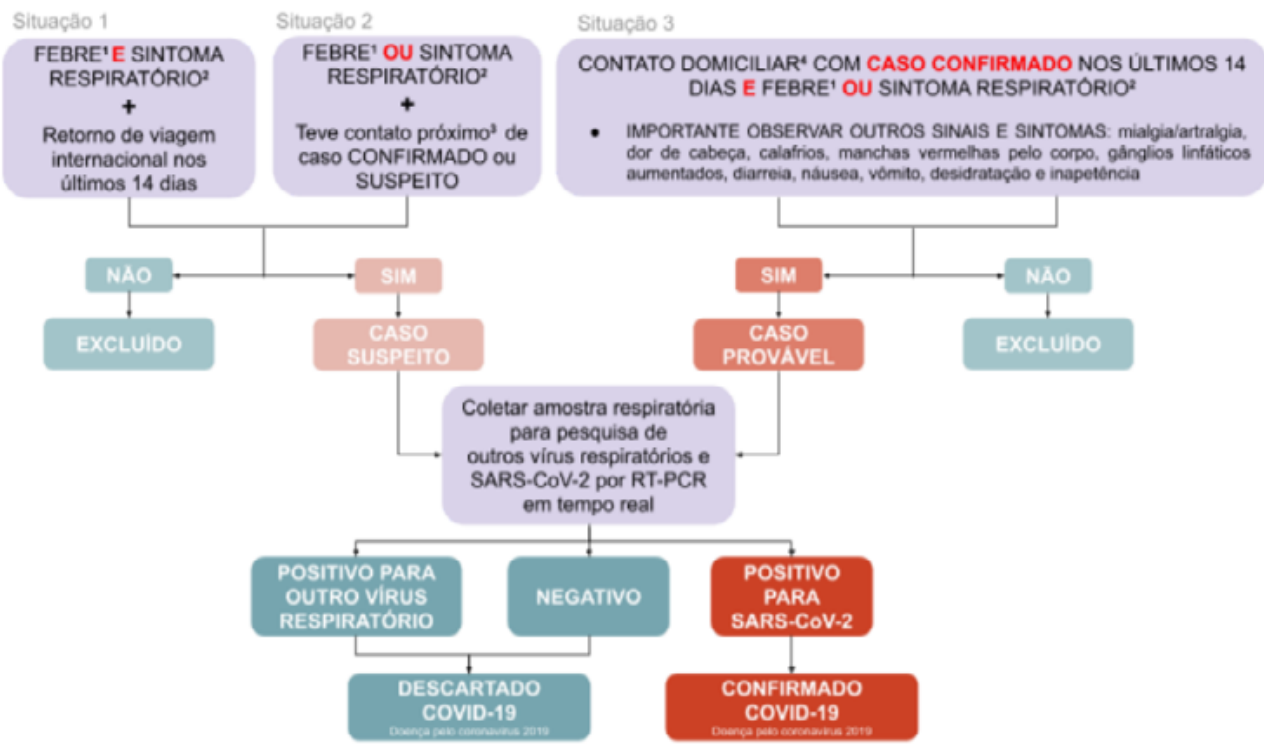

Fonte: Brasil (2020b).

e-SUS VE (e-SUS Vigilância Epidemiológica) Criado a partir da estrutura do E-SUS Atenção Básica (AB), uma ferramenta desenvolvida em 2013 tendo como objetivo organizar o funcionamento de diversos setores das Unidades Básicas de Saúde (UBS), o e-SUS VE alinha-se com a proposta mais geral de reestruturação dos Sistemas de Informação em Saúde do MS, especificamente a estratégia do SUS de uma informatização qualificada orientada ao SUS eletrônico. (BAHIA, 2020d) 
Disponibilizado para notificar pacientes com suspeita de COVID-19, em 27 de março, o e-SUS VE foi designado como o sistema notificador oficial do governo federal, implantado com o intuito de otimizar os registros da doença em todo o país. A notificação pode ser efetuada diretamente pelos usuários, os quais devem realizar um cadastro individual, e pelas instituições e/ou profissionais de saúde.

O e-SUS VE organiza quatro domínios de informações: "notificação", que traz dados do estado e município de notificação, bem como o número identificador; "identificação", domínio que coleta dados como Cadastro de Pessoa Física (CPF), entrageiro, profissão ligada à saúde, profissão ligada à segurança, Classificação Brasileira de Ocupações (CBO), Conselho Nacional de Saúde (CNS), nome, nome da mãe, data de nascimento, país de origem, sexo, raça/cor, passaporte, endereço de residência - Código de Endereçamento Postal (CEP), estado e município, logradouro, bairro - e telefone; "dados clinicos epidemiológicos", como data da notificação, data de inicio de sintomas, sintomas, condições prévias e teste - estado do teste, data da coleta, tipo de teste, resultado -; e "Controle de encerramento de caso" que cuida da classificação final, evolução do caso e data de encerramento do caso. ${ }^{8}$

\section{Sivep-Gripe}

O Sivep-Gripe foi criado para suportar as ações da vigilância de influenza tendo como foco principal a identificação dos principais vírus respiratórios em circulação, a fim de subsidiar a composição da vacina contra influenza e monitorar a demanda para a doença.

Para dar conta dos casos da COVID-19, o Sivep-Gripe necessitou ser atualizado. Foram inseridas cinco variáveis na ficha

8 Vide ficha de notificação em anexo. 
de notificação de SRAG hospitalizado e ou óbito por SRAG com intuito de captar e registrar no sistema os casos de SRAG que possuem histórico de viagem internacional e suspeitos para o COVID19. (BOLETIM EPIDEMIOLÓGICO INFECÇÃO HUMANA PELO NOVO CORONAVÍRUS, 2020c) A variável “Ocupação”, incluída em 31 de março de 2020 na ficha de registro individual dos casos de SRAG hospitalizados, e que segue em acordo com a CBO, destina-se a monitorar as tendências na incidência entre os trabalhadores essenciais e profissionais de saúde. (BOLETIM EPIDEMIOLÓGICO INFECÇÃO HUMANA PELO NOVO CORONAVÍRUS, 2020e)

Como o Sivep-Gripe permite acompanhar o histórico do paciente no hospital até o desfecho, é possível coletar informações sobre a data de internação; caso haja, a data de ingresso na Unidade de Terapia Intensiva (UTI); e a data de saída do hospital. Além disso, a evolução do caso também é acompanhada uma vez que o sistema registra a classificação final como confirmados, suspeitos ou prováveis, bem como registra o resultado e data de testagem.

Assim, a grosso modo, a partir do conjunto de informações registrados nesse sistema, é possível obter dados do paciente, dados de residência, dados clínicos e epidemiológicos, dados de atendimento, dados laboratoriais e a conclusão do caso.

\section{GAL - Dados laboratoriais}

O sistema GAL, desenvolvido pelo MS, por intermédio da Coordenação Geral de Laboratório de Saúde Pública (CGLLAB), em parceria com o Datasus, em 2008, tem por finalidade melhorar a coleta, o controle e o fluxo de informações relevantes que subsidiam os exames de doenças de média e alta complexidade. (PAULA JÚNIOR et al., 2017)

A utilização do GAL visa fortalecer o fluxo de informações de vigilância laboratorial nos âmbitos municipal, distrital, estadual 
e federal. Para fazer uso do sistema, os estabelecimentos de saúde, laboratórios municipais de referência regionais e laboratório estadual de referência regional devem ter cadastro no GAL. E o acesso aos resultados dos exames somente é permitido à unidade de saúde que cadastrou a amostra.

A coleta e cadastro no GAL de amostras para investigação de COVID-19 faz uso da ficha de notificação de caso suspeito própria para coronavírus, bem como da ficha de requisição do GAL. Processadas no Lacen, as amostras que chegarem sem as respectivas fichas não são analisadas. $O$ cadastro faz uso da estrutura da pesquisa para influenza visto que o sistema é uma fonte de dados para a Vigilância Sentinela da Síndrome Gripal (VSSG) no Brasil. (PAULA JÚNIOR et al., 2017) Dessa forma, o diagnóstico laboratorial ocorre nos Centros Nacionais de Influenza (NIC) - sigla em inglês para National Influenza Center. A amostra deve ser cadastrada como uma especificação da investigação da influenza humana por novo subtipo: novo coronavírus (2019nCoV). (BOLETIM EPIDEMIOLÓGICO INFECÇÃO HUMANA PELO NOVO CORONAVÍRUS, 2020b)

A coleta da amostra difere entre serviços de saúde públicos e privados. Para o caso dos públicos, só é necessário a coleta de uma amostra respiratória, devendo ser encaminhada com urgência para o Lacen. Já para os serviços privados, há necessidade de coleta de duas amostras respiratórias ou uma amostra que possa ser divida em duas, sendo uma delas enviadas ao Lacen. (BOLETIM EPIDEMIOLÓGICO INFECÇÃO HUMANA PELO NOVO CORONAVÍRUS, 2020b)

Uma vez diagnosticado qualquer vírus respiratório no laboratório privado, o resultado será válido para conduta clínica e retirada do paciente do isolamento. E deverá ser comunicado imediatamente para o Centro de Operações de Emergência do Ministério 
da Saúde. ${ }^{9}$ A confirmação laboratorial do agente etiológico será validada pelo Lacen e pelo NIC. O Lacen enviará o resultado para o solicitante, por e-mail. (BOLETIM EPIDEMIOLÓGICO INFECÇÃO HUMANA PELO NOVO CORONAVÍRUS, 2020b)

O GAL organiza as informações sobre a requisção, sobre o paciente - nome, idade, data de nascimento, sexo, documentos de identificação, município de residência, zona -, sobre a amostra/ exame - data da coleta, exame solicitado - e sobre o agravo (CID, CNES, município de notificação). (BOLETIM EPIDEMIOLÓGICO INFECÇÃO HUMANA PELO NOVO CORONAVÍRUS, 2020b)

\section{Os dados e a experiência da notificação a partir dos dados do estado da Bahia e do município de Salvador}

Esta seção tem como principais objetivos mostrar os dados que devem ser obtidos a partir das fichas de notificação dos sistemas que fazem o monitoramento dos casos de COVID-19, as dificuldades, os desafios da notificação segundo os dados do estado da Bahia e do município de Salvador.

\section{A construção da base de casos}

A busca e monitoramento de casos suspeitos e confirmados de COVID-19, na perspectiva da investigação epidemiológica no âmbito municipal e estadual, ocorre a partir da integração dos dados dos casos contidos no e-SUS VE, Sivep-Gripe e GAL.

Diariamente, o arquivo eletrônico - planilha de casos - é atualizado, contendo os casos confirmados e acumulados de COVID-19, alimentado a partir das informações coletadas de SG/COVID-19

9 A comunicação deve ser realizada através do e-mail: coe@saude.gov.br. 
notificados no e-SUS VE, da SRAG notificados no Sivep-Gripe e dos exames laboratoriais contidos no GAL. A busca de novas ocorrências e a verificação da situação de casos preexistentes ocorrem a partir da recuperação do registro do paciente por meio do seu CPF, nome, nome da mãe, data nascimento e município residência.

Em termos gerais, o processo envolve:

1. Verificar se há registros novos no e-SUS VE;

2. Verificar se há ocorrências de casos novos restritos ao âmbito do Sivep-Gripe;

3. Verificar no GAL se o paciente identificado na planilha de casos fez algum exame e o resultado do teste. Caso o registro seja encontrado e o teste tenha sido realizado, as mudanças de status alimentam as variáveis de classificação e investigação final, que sempre virão do Lacen: teste "não detectável" é classificado como descartado laboratorialmente; "teste inconclusivo", com necessidade de recoleta, mantém o caso como suspeito;

4. Verificar se há ocorrência de registros presentes na planilha de casos no Sivep-Gripe para identificar casos de óbito, de internamento, a ocorrência e o resultado de exames laboratoriais etc.

No que tange à investigação de exames, importante deixar claro que prevalece o resultado obtido do GAL. Contudo, quando o indivíduo não é encontrado na base GAL, mas é localizado no Sivep-Gripe, observa-se se há alguma indicação de que houve testagem, e como foi esse teste: se houve exame laboratorial e se o exame foi positivo. Com essas informações, o status de suspeito do indivíduo que estava na planilha de casos vai para confirma e acrescenta-se todas as informações que vem do Sivep-Gripe na linha do paciente.

Outra estratégia de atualização de casos consistia na busca ativa, a partir dos dados recebidos pelo CIEVS. A ação consistia 
em acompanhar e monitorar junto aos centros de saúde e ao GAL o resultado laboratorial, já que os exames realizados por laboratórios credenciados ao Lacen-BA são registrados no e-SUS VE, mas não estão disponíveis no GAL, ${ }^{10}$ bem como realizar uma investigação detalhada dos casos de COVID-19 que são captados pelos sistemas de informação (e-SUS Notifica ou Sivep-Gripe) - O rastreamento de contatos. Visto que uma vez confirmado o caso, é feito um processo de investigação por meio de contato telefônico com o próprio doente e/ou familiar, para levantamento de informações necessárias para investigação epidemiológica do caso: histórico de viagens, identificar quem entrou em contato direto, dentre outros aspectos. (BRASIL, 2020c) Essas ações impactam diretamente na melhoria da qualidade do dado e na completude das variáveis (endereço, CPF, dentre outras).

Além disso, a vigilância ativa contribui para o adequado encerramento dos casos, uma vez que ela também realiza o controle de óbitos - os casos de óbitos confirmados nos sistemas Sivep-Gripe e e-SUS VE devem ser confrontados e validados com a correta definição da sua causa básica no SIM. Essa ação tem como propósito a avaliação das circunstâncias em que os óbitos ocorreram, a fim de contribuir para a identificação do número real de óbitos e a produção de informações em tempo hábil e a qualificação das informações sobre mortalidade. (BAHIA, 2020e)

Após a unificação, a base de dados resultante, de forma geral, retém informações da notificação, da pessoa e do caso (Figura 3).

10 Ações dizem respeito à vigilância laboratorial: pesquisa dos resultados de exames para confirmação diagnóstica para COVID-19 - seja de exames realizados por laboratórios públicos, Laboratório Central de Saúde Pública Professor Gonçalo Moniz (Lacen) e/ou laboratórios privados. 
Figura 3 - Modelo Conceitual da base de dados COVID-19

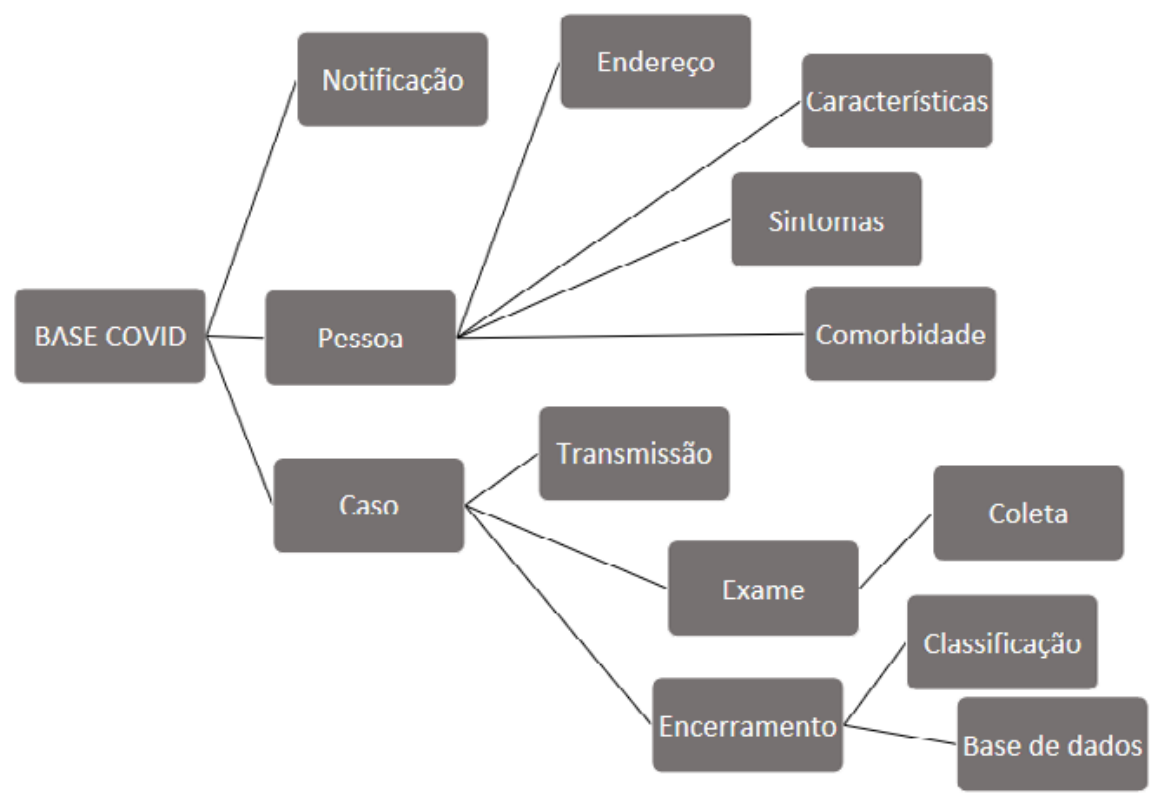

Fonte: elaborada pelos autores.

Importante salientar que as bases do estado e do município têm estruturas diferentes, ainda que o processo de geração e controle da planilha de casos utilize os mesmos sistemas. Isso porque cada município tem responsabilidade e autonomia de utilizar a metodologia mais adequada à sua realidade, considerando a dinâmica dos dados e veracidade das informações, contanto que esta se apresenta coerente e baseada nos protocolos ministeriais e portarias estaduais. 


\section{A planilha de casos da Sesab}

A partir do dia 16 de maio de 2020, a Secretaria da Saúde do Estado da Bahia (Sesab) automatizou o processo de integração das bases de dados epidemiológicos e laboratoriais dos governos federal, estadual e municipais. À época, apenas a Bahia e mais três outros estados conseguiram desenvolver uma solução tecnológica que permitisse consolidar as três principais bases de dados do MS em conjunto. A partir desse sistema, foi possível baixar e integrar os dados dos casos contidos no e-SUS VE, Sivep-Gripe e GAL e consolidá-los com as bases do estado e dos municípios. O resultado dessa automatização permitiu acessar também todos os casos confirmados por critério clínicos, testes rápidos e testes realizados em unidades privadas, além dos casos confirmados laboratorialmente. Ficando a busca ativa apenas concentrada na investigação epidemiológica do caso e nas interações com os municípios, já que após melhoria e a atualização da base (Figura 4), os novos casos de pacientes (extração do dia) são validados pelos municípios em até 24h. (BAHIA, 2020b, BOLETIM EPIDEMIOLÓGICO COVID-19, 2020b) 
Figura 4 - Fluxo de integração das bases pela Sesab

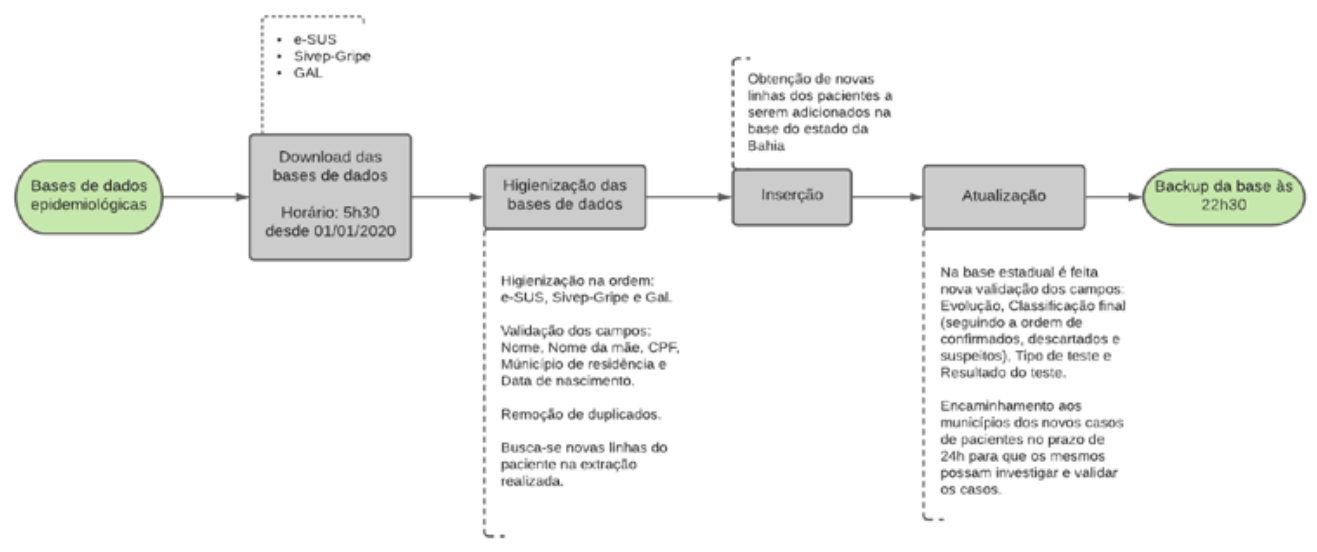

Fonte: adaptado de Boletim Epidemiológico COVID-19 (2020b).

A planilha de casos da COVID-19 do estado da Bahia da SESAB traz informações dos casos confirmados, suspeitos e descartados. Esses dados, que datam a partir de 28 de fevereiro de 2020, alimentam o Boletim Epidemiológico da Coordenação de Investigação e Informação Estratégica de Vigilância em Saúde (CIEVS/SESAB) e tem a seguinte estrutura: 
Figura 5 - Estrutura dos dados de casos da Sesab

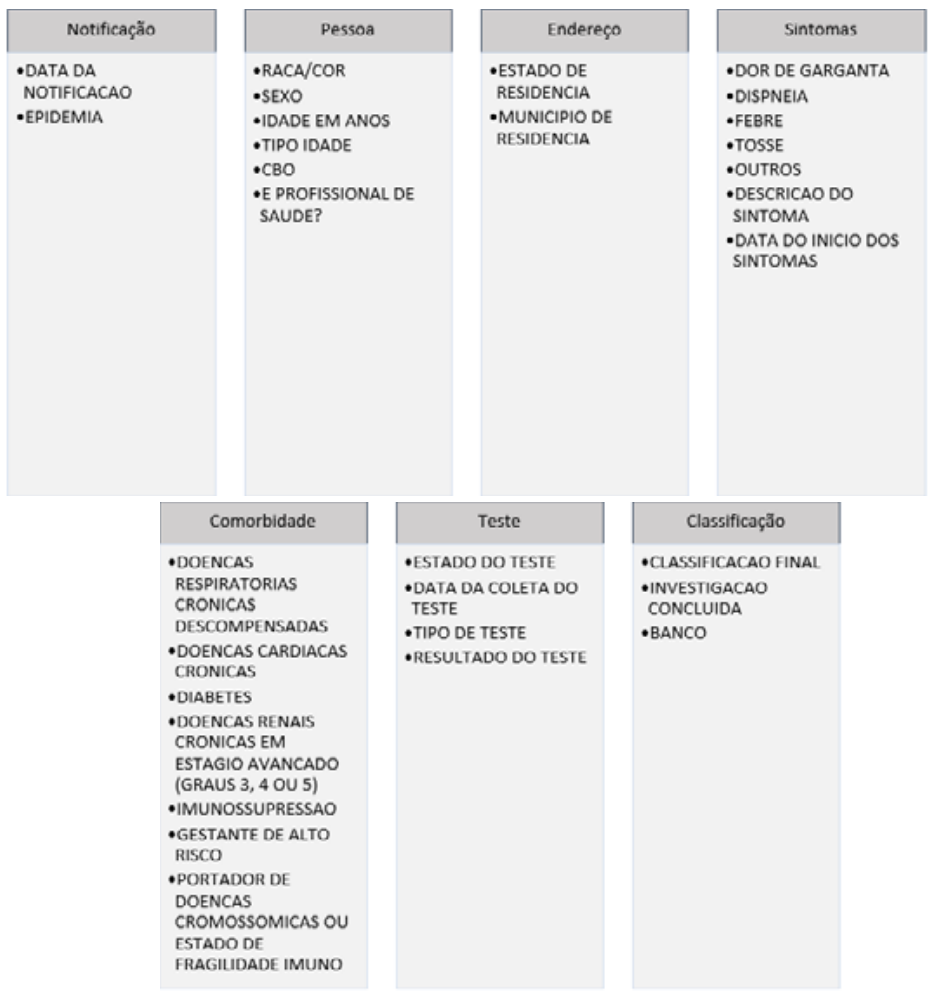

Fonte: elaborada pelos autores.

Os dados de óbitos são emitidos em um planilha em separado, isso porque observa-se que os óbitos por COVID-19, frutos da unificação das bases e da atuação das equipes de vigilâncias na investigação para a confirmação dos casos, tende a indicar valores maiores do que o informado no SIM. (BAHIA, 2020d, 2020e) São informações geradas pós-investigação e qualificação através de consulta ao SIM, conforme indica a Figura 6. 
Figura 6 - Fluxo de validação de óbitos pela Sesab

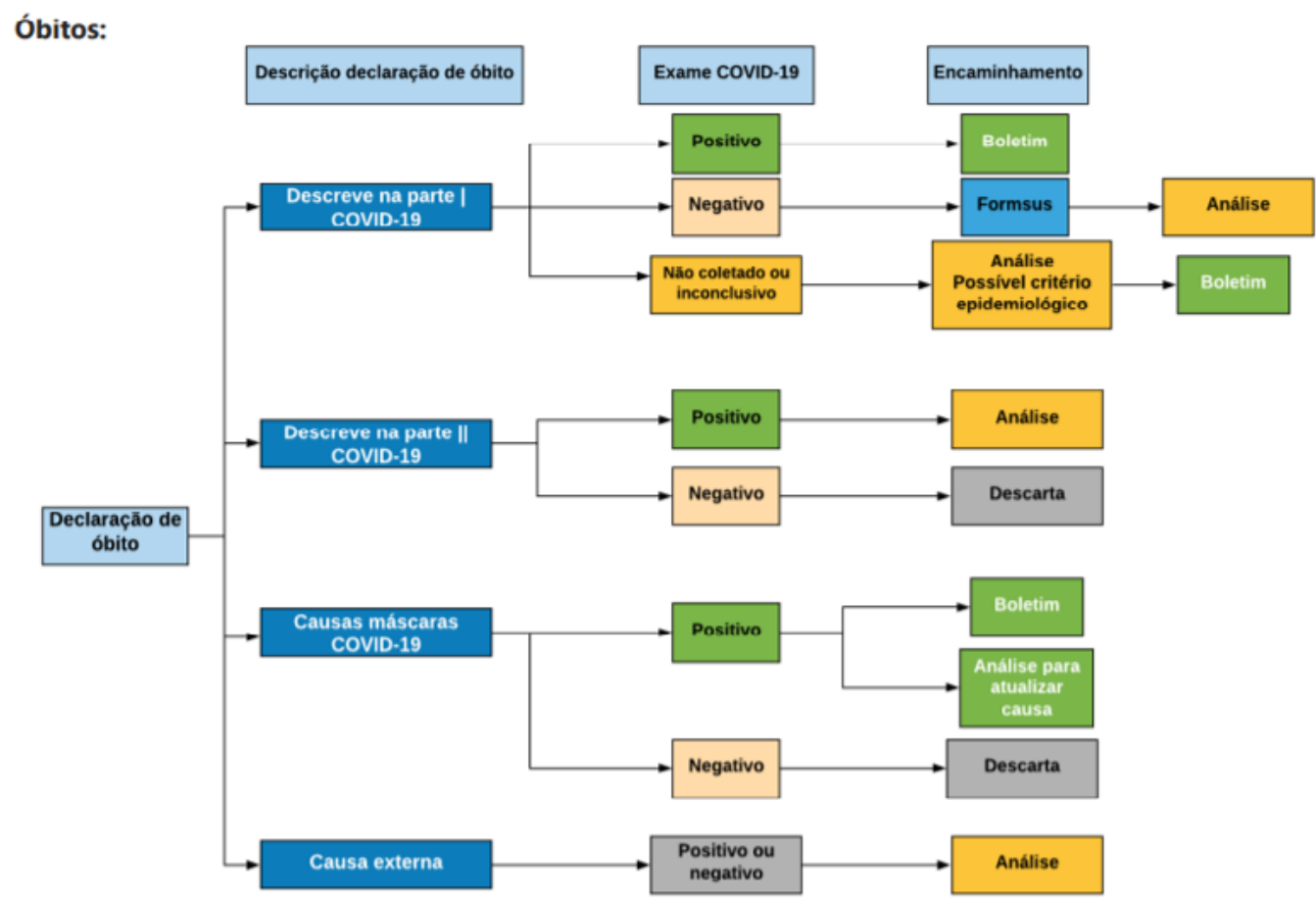

Fonte: Boletim Epidemiológico COVID-19 (2020b). 


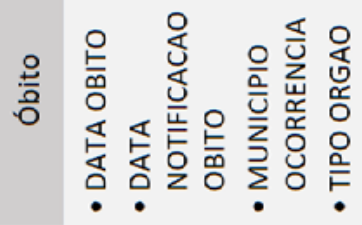

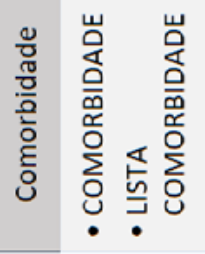

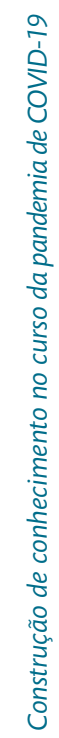

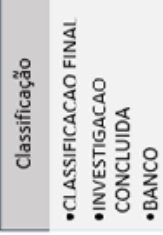

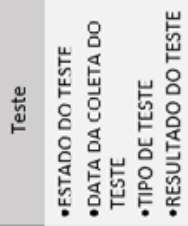
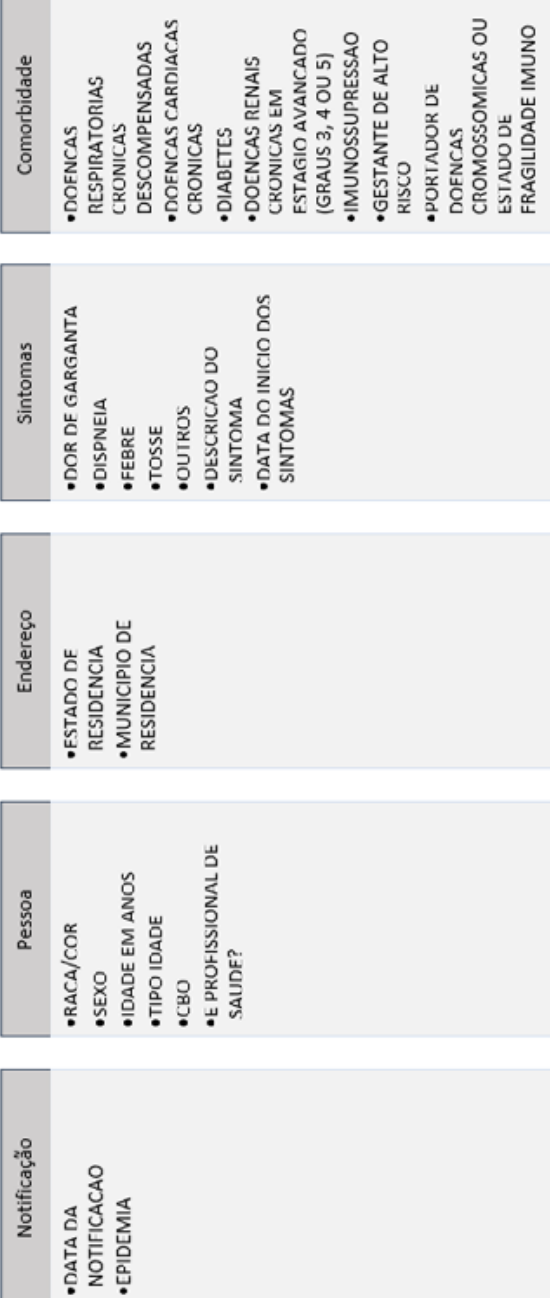


\section{A planilha de casos da SMS}

Para a SMS, os registros baixados das bases são priorizados pela evolução - óbito, cura, internados, domiciliar - e resultado teste confirmado, descartado, suspeito. Esses são os critérios definidos para selecionar os registros que comporão o banco de dados municipal. A planilha de casos do município segue a estrutura de variáveis do e-SUS e a atualização é demarcada pelo registro selecionado de acordo com os critérios. O processo de integração dos dados da SMS ocorre tanto de forma manual quanto automática, a qual ocorre de forma gradativa desde junho de 2020.

A vigilância do óbito realizada pela Diretoria de Vigilância da Saúde (DVIS), por meio da Subcoordenadoria de Informação em Saúde (SUIS), também tem como sua fonte principal de dados sobre o óbito a Declaração de Óbito (D.O.). No dia 7 de abril de 2020, foi emitida a Nota Técnica ${ }^{\circ} 08$ (SUIS/DVIS/SMS) “Solicitando aos estabelecimentos de saúde e médicos autônomos o envio da D.O por e-mail em até 24 horas após o óbito" para tomadas de decisões imediatas, bem como a digitação da D.O. no SIM, de acordo com orientação do MS. (BAHIA, 2020e)

Importante deixar claro que há diferenças entre os números indicados pelo SIM e os casos de óbitos contabilizados pelo e-SUS VE e Sivep-Gripe. Por isso, as informações contidas na D.O. são complementadas após o pareamento destas com os dados levantados do Sivep- Gripe e pelo e-SUS VE e a ação de investigação do óbito. (BAHIA, 2020e)

Com isso, os registros em fase de monitoramento dos dados quanto à vigilância laboratorial terão seus status classificados como "aguarda exame", "sem registro GAL para COVID-19”, "sem coleta" e "inconclusivo". Os óbitos que estão com status "não detectado para COVID-19” estão em outra fase de investigação, que é a vigilância clínica com consulta ao banco Sivep-Gripe e, caso não tenha registro nessa base de dados, seguirá para 


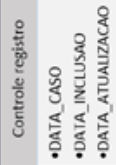

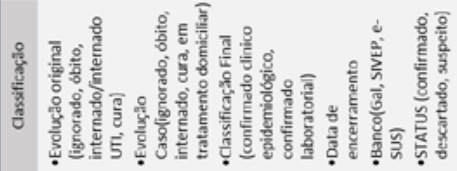

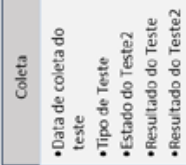

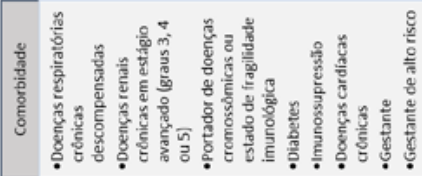

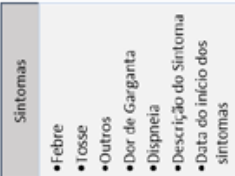

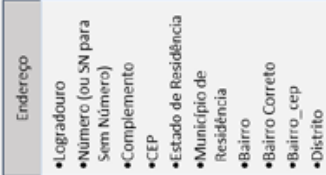

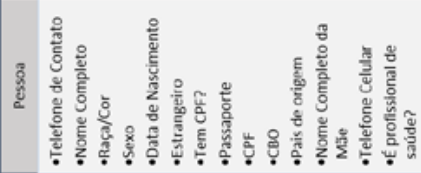

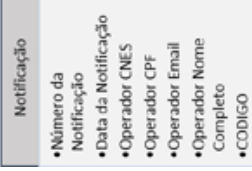
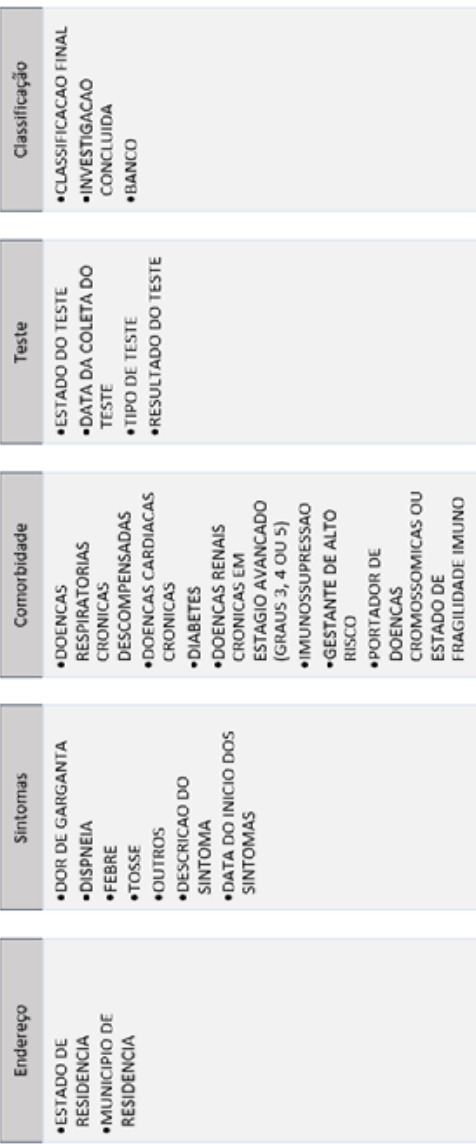

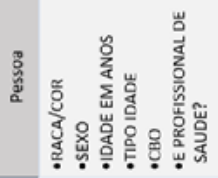

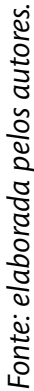


investigação nos Estabelecimentos de Atenção à Saúde (EAS) e/ ou para a Autópsia Verbal (AV), de acordo com o local de ocorrência do óbito (unidade de saúde ou domicílio, respectivamente). Processo que segue a orientação do MS4, no Guia de Vigilância Epidemiológica Emergência de Saúde Pública de Importância Nacional pela Doença pelo Coronavirus 2019, divulgado em 3 de abril de 2020 - "Resultados negativos não excluem a infecção por SARS-CoV2". (BAHIA, 2020e)

A planilha de acompanhamento do óbito por COVID-19 é, então, um banco interno sob gestão da SUIS (BAHIA, 2020e) e tem a seguinte estrutura:

Figura 9 - Estrutura dos dados de óbito da SMS
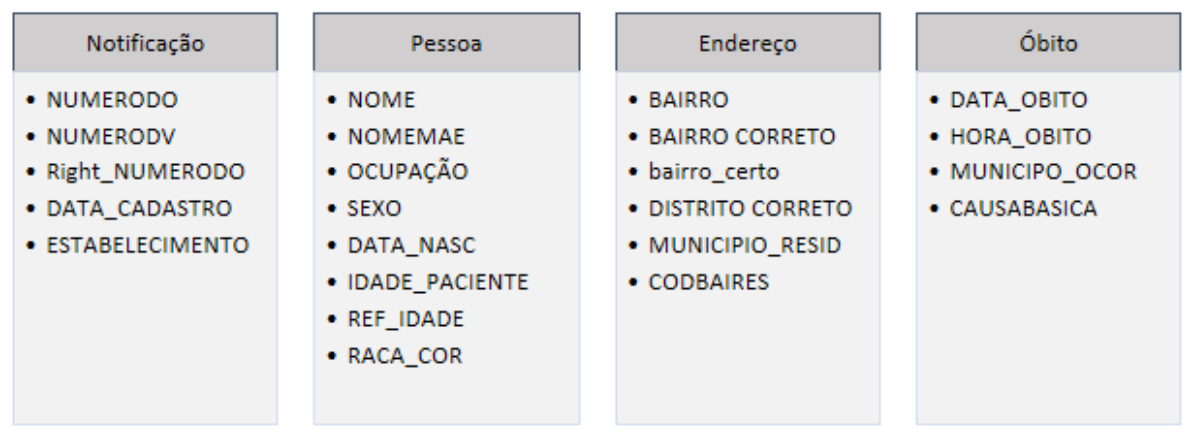

Fonte: elaborada pelos autores.

\section{Divulgação dos dados: estado x município}

Diferenças em relação ao número de casos: município e estado diferem no que diz respeito à divulgação de casos confirmados. Enquanto o primeiro divulga o número de casos de acordo com a data de início de sintomas e data de coleta - para os indivíduos assintomáticos -; o segundo o faz por meio da data de extração da base. O que justifica as diferenças encontradas quando 
comparamos o número de casos confirmados na cidade de Salvador a partir dos boletins das duas secretarias, por exemplo, no dia 3 de outubro, segundo a SMS, existiam 87.124 casos confirmados (SALVADOR, 2020), enquanto que pela Sesab, o número de confirmados foi 86.386. (BAHIA, 2020g)

Diferenças em relação ao número de óbitos: observa-se diferenças entre o número de óbitos por COVID-19 indicados pelo SUIS/SMS ${ }^{11}$ e os publicizados pelo CIEVS/Bahia ${ }^{12}$ através dos seus boletins diários. Os casos informados pelo estado tendem a apresentar valores maiores do que o informado pelo município. A diferença pode ser explicada pela metodologia de criação das bases, pelo horário em que os dados oficiais fornecidos pelos sistemas de informação são coletados e pelos critérios adotados para o processo de qualificação da informação de óbitos.

\section{As variáveis-chaves para a análise e a evolução da qualidade dos dados ao longo do tempo}

\section{A planilha de casos da SMS}

A partir das bases de dados disponibilizadas pela SMS, foram encontradas dificuldades no que diz respeito à obtenção e à situação de algumas variáveis úteis, podendo interferir na qualidade da análise dos dados. As principais dificuldades podem ser resumidas em:

a. Mudança do sistema do FormSus/RedCap para o e-SUS VE e a dificuldade de migração trouxeram perdas de variáveis:

11 Os casos do munícipio podem ser acompanhados pelo site: http://www.saude. salvador.ba.gov.br/covid/indicadorescovid/.

12 Os casos do estado são divulgados no portal de transparência: https://bi.saude. ba.gov.br/transparencia/. 
como data de encerramento, data do óbito, dados de exames, entre outras;

b. Variáveis com preenchimentos diversos ou seja, vários tipos são preenchidos para um mesmo campo, a exemplo da variável "Histórico de Viagem" que pode conter tanto informações de data, quanto informes textuais a respeito da situação de viagem do paciente;

c. Compreensão de variáveis: vide a dificuldade de identificar bairros oficiais para o município. Apesar da existência de documentos reguladores, como "a relação de bairros por distrito" e "bairros Salvador (de-para)". A variação de preenchimento, dificulta a validação do dado para classificação de determinados bairros;

d. Incompletude de variáveis: de variáveis-chaves importantes para o controle da notificação do caso.

Com relação ao último tópico, é importante mencionar que as bases iniciais apresentavam alto percentual de missing - valores faltantes - em variáveis consideradas importantes para monitoramento dos casos, como as utilizadas para definir o tempo de início para cada caso, como a data de notificação, data de início de sintomas e/ou data da coleta; variáveis de localização dos casos, como as variáveis de bairro e distrito sanitário, por exemplo. Além de variáveis de outra natureza.

Com o passar dos meses, houve um esforço para melhorar a qualidade das informações das bases de dados, como as variáveis de endereços dos casos, como bairros e distritos sanitários, inicialmente, feita a partir da busca ativa e, tempos depois, a partir da busca nos sistema da rede VIDA - Sistema Integrado de Saúde, além de esforços para preenchimento automático do distrito sanitário a partir da informação do bairro. Foi observado que, no final de março de 2020, o percentual de incompletude da variável de bairro ultrapassou $70 \%$, mas houve um decréscimo gradual com 
o passar dos meses, chegando a menos de $5 \%$ no final do mês de outubro. No que diz respeito ao distrito sanitário, observou-se que até início do mês de junho, as bases apresentavam altos percentuais de incompletude, chegando a $88,24 \%$ no mês de maio e somente no final do mês de setembro começou a apresentar valores mais baixos no percentual de incompletude, ficando em torno de $6 \%$ no final do mês de outubro, conforme resume a Tabela 1.

É importante ressaltar que também houve melhoria no preenchimento da variável de data de notificação, por exemplo, após integração dos sistemas - e-SUS VE, Sivep-Gripe e GAL - e a inserção da variável raça/cor, oriunda do e-SUS VE.

Tabela 1 - Incompletude das variáveis de bairro e distrito sanitário segundo data da base de dados - SMS, 2020

\begin{tabular}{|c|c|c|c|c|c|}
\hline \multirow{2}{*}{$\begin{array}{c}\text { Data da } \\
\text { base }\end{array}$} & \multirow{2}{*}{ Total } & \multicolumn{2}{|c|}{ Bairro } & \multicolumn{2}{|c|}{ Distrito } \\
\hline & & $\mathbf{N}$ & $\%$ & $\mathbf{N}$ & $\%$ \\
\hline $27 / 03 / 2020$ & 2.655 & 1.900 & 71,56 & 1.873 & 70,55 \\
\hline $31 / 03 / 2020$ & 2.691 & 1.903 & 70,72 & 1.876 & 69,71 \\
\hline $07 / 04 / 2020$ & 5.469 & 2.335 & 42,70 & 4.575 & 83,65 \\
\hline $17 / 04 / 2020$ & 6.199 & 2.474 & 39,91 & 5.003 & 80,71 \\
\hline $27 / 04 / 2020$ & 10.193 & 3.709 & 36,39 & 8.914 & 87,45 \\
\hline $01 / 05 / 2020$ & 14.648 & 4.886 & 33,36 & 13.369 & 91,27 \\
\hline $09 / 05 / 2020$ & 20.297 & 5.912 & 29,13 & 17.803 & 87,71 \\
\hline $17 / 05 / 2020$ & 22.268 & 7.295 & 32,76 & 19.649 & 88,24 \\
\hline $01 / 06 / 2020$ & 27.216 & 9.762 & 35,87 & 21.072 & 77,43 \\
\hline $28 / 06 / 2020$ & 109.165 & 11.019 & 10,09 & 9.651 & 8,84 \\
\hline $11 / 07 / 2020$ & 120.602 & 11.494 & 9,53 & 9.884 & 8,20 \\
\hline $14 / 07 / 2020$ & 136.424 & 14.216 & 10,42 & 15.636 & 11,46 \\
\hline
\end{tabular}




\begin{tabular}{c|c|c|c|c|c}
\hline \multirow{2}{*}{$\begin{array}{c}\text { Data da } \\
\text { base }\end{array}$} & Total & \multicolumn{3}{|c|}{ Bairro } & Distrito \\
\hline $\mathbf{2 2 / 0 7 / 2 0 2 0}$ & 147.390 & 13.420 & 9,11 & 31.099 & 21,10 \\
\hline $\mathbf{0 3 / 0 8 / 2 0 2 0}$ & 166.105 & 13.252 & 7,98 & 33.387 & 20,10 \\
\hline $\mathbf{2 4 / 0 8 / 2 0 2 0}$ & 187.947 & 15.442 & 8,22 & 36.513 & 19,43 \\
\hline $\mathbf{3 1 / 0 8 / 2 0 2 0}$ & 197.833 & 10.017 & 5,06 & 38.218 & 19,32 \\
\hline $\mathbf{1 5 / 0 9 / 2 0 2 0}$ & 216.660 & 10.542 & 4,87 & 41.795 & 19,29 \\
\hline $\mathbf{2 4 / 0 9 / 2 0 2 0}$ & 229.524 & 10.917 & 4,76 & 13.680 & 5,96 \\
\hline $\mathbf{1 6 / 1 0 / 2 0 2 0}$ & 253.925 & 12.278 & 4,84 & 14.992 & 5,90 \\
\hline $\mathbf{2 8 / 1 0 / 2 0 2 0}$ & 266.848 & 12.907 & 4,84 & 15.774 & 5,91 \\
\hline
\end{tabular}

Fonte: elaborada pelos autores.

\section{Considerações finais}

Apesar das iniciativas para o aprimoramento dos sistemas de informação, como resultado dos esforços e da capacidade técnica dos profissionais que atuam na VE, especialmente nos CIEVS, há dificuldades no manejo dos sistemas de informação que precisam ser superadas, em todos os níveis de gestão. (REIS et al., 2020) As principais dificuldades podem ser listadas a seguir:

1. O preenchimento incompleto de informações, com grande variação de qualidade entre os órgãos e instituições de saúde responsáveis pela coleta, tem dificultado a qualificação das informações. Além disso, as mudanças constantes no processo, instrumento e fluxo da notificação dos casos de COVID-19 também dificultam o processamento e análise dos dados para gerar informações ágeis; 
2. A dificuldade de integração das bases de dados de síndrome gripal, e-SUS VE e GAL, que não tem permitido uma avaliação da ocorrência real do COVID-19 e outras doenças respiratórias agudas, além de haver um atraso na identificação dos casos confirmados devido à demora na obtenção dos resultados dos exames laboratoriais;

3. Limitações do e-SUS VE, o qual diante do grande volume de casos notificados diariamente apresenta instabilidade e, como consequência, o download diário das bases para o monitoramento da pandemia pelos estados e municípios pode sofrer descontinuidade. Sendo o MS o principal detentor e centralizador das informações, desvirtua-se o objetivo principal do sistema de informação que é assegurar a disponibilidade de informações em todos os níveis de gestão, de modo eficiente e oportuno;

4. Outro problema do e-SUS VE é que ele cataloga casos suspeitos, mas não permite que nenhum hospital atualize as fichas epidemiológicas com os resultados de exames, quando são realizados. Apenas as secretarias de saúde e algumas poucas instituições conseguem fazer isso. (QUEIROZ, 2020)

5. O estímulo à autonotificação, ${ }^{13}$ estratégia do MS para aliviar o sistema de saúde para que possa concentrar esforços no atendimento a pacientes graves, também impactou no e-SUS VE, uma vez que tem contribuído para a subnotificação de casos;

6. Embora a notificação no Sivep-Gripe de casos suspeitos ocorra logo no momento da internação, os hospitais precisam ter cadastro para uso no sistema, além de infraestrutura operacional. Alguns hospitais ainda podem fazer uso de fichas de

13 Orientação dada à população com sintomas leves a observar eventual desenvolvimento da doença em casa. 
notificação de papel e dependerem de malote para enviá-las às unidades regionais de vigilância em saúde, encarregadas de inserir os dados no Sivep-Gripe (QUEIROZ, 2020);

7. O tempo decorrido entre o paciente ficar doente, procurar o serviço de saúde, ser internado e notificado no Sivep-Gripe, que pode impactar na subnotificação, na consistência da informação gerada e na contabilização de casos confirmados;

8. Duplicidade dos registros, na medida em que um caso pode ser notificado tanto no e-SUS VE quanto no Sivep-Gripe, caso a pessoa seja hospitalizada. É preciso buscar estratégias para eliminar as duplicidades, as localidades que não contam com a integração automática das bases de dados precisam analisar as fichas dos pacientes nas duas ferramentas e excluir, manualmente, as repetições. Um trabalho que demanda tempo e equipe. (QUEIROZ, 2020)

Nesse sentido, recomenda-se:

a. Tornar obrigatório o preenchimento do campo das variáveis importantes para análise de casos, tais como CPF, endereço do paciente, CEP;

b. Aprimorar os sistemas de informação para a COVID-19 (e-SUS, Sivep-Gripe/SRAG, GAL), a fim de que os dados sejam disponibilizados de forma integrada, ágil, oportuna, regular e de modo transparente, nos três níveis do SUS.

\section{Referências}

BAHIA. Secretaria da Saúde do Estado. e-SUS. Salvador, 2020a. Disponível em: http://www.saude.ba.gov.br/atencao-a-saude/dab/e-sus/. Acesso em: 29 out. 2020. 
BAHIA. Secretaria da Saúde. Sesab desenvolve sistema que integra bases de dados epidemiológicos do país. Salvador, 2020b. Disponível em: http://www.saude. ba.gov.br/2020/05/16/sesab-desenvolve-sistema-que-integra-bases-de-dadosepidemiologicos-do-pais/. Acesso em: 16 maio 2020.

BAHIA. Secretaria da Saúde. Superintendência de Vigilância e Proteção da Saúde Orientações para a vigilância do óbito por COVID-19. Normalização bibliográfica realizada por Maria Creuza Ferreira da Silva. 2. ed. Salvador: SESAB, 2020c.

BAHIA. Secretaria da Saúde do Estado. Superintendência de Vigilância e Proteção da Saúde. Orientações para a vigilância do óbito por COVID. 2. ed. Salvador: SESAB, 2020d.

BAHIA. Secretaria da Saúde. Superintendência de Vigilância e Proteção da Saúde. Diretoria de Vigilância Epidemiológica. Situação epidemiológica dos óbitos por Covid-19 em Salvador, Ba, 2020. Boletim Informativo, Salvador, n. 3, 19 jun. 2020. 2020e.

BOLETIM EPIDEMIOLÓGICO COVID-19. Salvador: Secretaria da Saúde, n. 193, 3 out. 2020. Salvador: Sesab, 2020a. Disponível em: http://www.saude.ba.gov.br/ wp-content/uploads/2020/10/BOLETIM_ELETRONICO_BAHIAN_193_03102020. pdf. Acesso em: 22 out. 2020.

BOLETIM EPIDEMIOLÓGICO COVID-19. Salvador: Secretaria da Saúde, n. 218, 28 out. 2020. Salvador: Sesab, 2020 b.

BOLETIM EPIDEMIOLÓGICO INFECÇÃO HUMANA PELO NOVO CORONAVÍRUS (2019-NCOV). Brasília, DF: Ministério da Saúde, n. 1, jan. 2020a.

BOLETIM EPIDEMIOLÓGICO INFECÇÃO HUMANA PELO NOVO CORONAVÍRUS (2019-NCOV). Brasília, DF: Ministério da Saúde, n. 2, fev. 2020b.

BOLETIM EPIDEMIOLÓGICO INFECÇÃO HUMANA PELO NOVO CORONAVÍRUS (2019-NCOV). Brasília, DF: Ministério da Saúde, n. 3, 21 fev. 2020c.

BOLETIM EPIDEMIOLÓGICO INFECÇÃO HUMANA PELO NOVO CORONAVÍRUS (2019-NCOV). Brasília, DF: Ministério da Saúde, n. 5, 14 maio 2020d.

BOLETIM EPIDEMIOLÓGICO INFECÇÃO HUMANA PELO NOVO CORONAVÍRUS (2019-NCOV). Brasília, DF: Ministério da Saúde, n. 42, 21 out. 2020e.

BRASIL. Decreto n ${ }^{\circ}$ 7.616, de 17 de novembro de 2011. Dispõe sobre a declaração de Emergência em Saúde Pública de Importância Nacional - ESPIN e institui a Força Nacional do Sistema Único de Saúde - FN-SUS. Diário Oficial da União, Brasília, DF, 18 nov. 2011a. 
BRASIL. Ministério da Saúde. Fluxo de notificação Covid-19. Brasília, DF: 2020a. Disponível em: https://egestorab.saude.gov.br/image/?file=20200429

_N_1588170543994fluxodenotificacaocovid19_2350435781724030115.pdf. Acesso em: 29 out. 2020.

BRASIL. Ministério da Saúde. Secretaria de Vigilância em Saúde. Departamento de Vigilância em Saúde Ambiental e Saúde do Trabalhador. Plano de resposta às emergências em saúde. Brasília, DF: Ministério da Saúde, 2014.

BRASIL. Ministério da Saúde. Definição de caso e notificação. Brasília, DF, 2020 b. Disponível em: https://coronavirus.saude.gov.br/definicao-de-caso-e-notificacao. Acesso em: 9 jun. 2020.

BRASIL. Ministério da Saúde. Emergência de Saúde Pública de Importância Internacional (ESPII). Protocolo De Vigilância Epidemiológica Da Influenza Pandêmica (H1N1)2009: notificação, investigação e monitoramento. Brasília, DF, 2010a. Disponível em: http://www.fmt.am.gov.br/layout2011/dam/h1n1/ documentos/Protocolo_ve_influenza_2010.pdf. Acesso em: 29 out. 2020.

BRASIL. Ministério da Saúde. Guia de vigilância epidemiológica: vigilância de síndromes respiratórias agudas COVID-19, 05 de agosto de 2020. Brasília, DF: Ministério da Saúde, 2020c.

BRASIL. Ministério da Saúde. Plano brasileiro de preparação para enfrentamento de uma pandemia de Influenza: IV versão. Brasília, DF, 2010b. Disponível em: http:// bvsms.saude.gov.br/bvs/publicacoes/plano_brasileiro_pandemia_influenza_IV.pdf. Acesso em: 29 out. 2020.

BRASIL. Ministério da Saúde. Secretaria de Vigilância em Saúde. Portaria $n^{\circ} 1.865$, de 10 de agosto de 2006. Estabelece a Secretaria de Vigilância em Saúde como Ponto Focal Nacional para o Regulamento Sanitário Internacional (2005) junto à Organização Mundial da Saúde. Brasília, DF, 2006. Disponível em: https:// bvsms.saude.gov.br/bvs/saudelegis/gm/2006/prt1865_10_08_2006.html. Acesso em: 19 nov. 2020.

BRASIL. Ministério da Saúde. Secretaria de Vigilância em Saúde. Coordenação Geral de Doenças Transmissíveis. Vigilância sentinela de Síndrome Gripal (SG) no Brasil. Brasília, DF, 2015. Disponível em: https://www.saude.pr.gov.br/sites/ default/arquivos_restritos/files/documento/2020-04/vigilancia_sentinela_de_sg_no_ brasil_final.pdf. Acesso em: 29 out. 2020. 
BRASIL. Ministério da Saúde. Secretaria de Vigilância em Saúde. Portaria $n^{\circ} 36$, de 22 de dezembro de 2003. Institui o Comitê Técnico para elaboração do Plano de Preparação para a Pandemia de Influenza no Brasil e dá outras providências. Brasília, DF, 2003. Disponível em: http://bvsms.saude.gov.br/bvs/saudelegis/ svs/2003/prt0036_22_12_2003.html. Acesso em: 22 out. 2020.

BRASIL. Ministério da Saúde. Secretaria de Vigilância em Saúde. Portaria n 188 , de 3 de fevereiro de 2020. Declara Emergência em Saúde Pública de importância Nacional (ESPIN) em decorrência da Infecção Humana pelo novo Coronavírus (2019-nCoV). Diário Oficial da União: seção 1, Brasília, DF, n. 24-A, p. 1, 4 fev. 2020c. Disponível em: https://www.in.gov.br/en/web/dou/-/portaria-n188-de-3-de-fevereiro-de-2020-241408388?inheritRedirect=true\&redirect=\% 2Fweb\%2Fguest\%2Fsearch\%3Fstart\%3D1\%26qSearch\%3DEstado\%2520de\%2520emerg\%25C3\%25AAncia\%2520fevereiro\%25202020l. Acesso em: 22 out. 2020.

BRASIL. Ministério da Saúde. Secretaria de Vigilância em Saúde. Portaria $n^{\circ} 104$, de 25 de janeiro de 2011. Define as terminologias adotadas em legislação nacional, conforme o disposto no Regulamento Sanitário Internacional 2005 (RSI 2005), a relação de doenças, agravos e eventos em saúde pública de notificação compulsória em todo o território nacional e estabelece fluxo, critérios, responsabilidades e atribuições aos profissionais e serviços de saúde. Brasília, DF, 2011b. Disponível em: http://bvsms.saude.gov.br/bvs/saudelegis/gm/2011/ prt0104_25_01_2011.html. Acesso em: 19 nov. 2020.

CARMO, E. H.; PENNA, G.; OLIVEIRA, W. K. de. Emergências de saúde pública: conceito, caracterização, preparação e resposta. Estudos Avançados, São Paulo, v. 22, n. 64, p. 19-32, dez. 2008. DOI: http://dx.doi.org/10.1590/ S0103-40142008000300003. Disponível em: http://www.scielo.br/scielo. php?script=sci_arttext\&pid=S0103-40142008000300003\&lng=en\&nrm=iso. Acesso em: 10 set. 2020.

COSTA, L. M. C. da. Avaliação do sistema de vigilância epidemiológica da influenza no Brasil, 2010-2013. 2015. Tese (Doutorado em Ciências da Saúde) - Faculdade de Ciências da Saúde, Universidade de Brasília, Brasília, DF, 2015.

LIMA, Y. O. R.; COSTA, E. A. Implementação do Regulamento Sanitário Internacional (2005) no ordenamento jurídico-administrativo brasileiro. Ciência \& Saúde Coletiva, Rio de Janeiro, v. 20, n. 6, p. 1773-1783, 2015. 
PAULA JÚNIOR, F. J. de et al. Sistema Gerenciador de Ambiente Laboratorial - GAL: avaliação de uma ferramenta para a vigilância sentinela de síndrome gripal, Brasil, 2011-2012. Epidemiologia e Serviços de Saúde, Brasília, DF, v. 26, n. 2, p. 339-348, jun. 2017. DOI: https://doi.org/10.5123/s1679-49742017000200011. Disponível em: http://www.scielo.br/scielo.php?script=sci_arttext\&pid =S2237-96222017000200339\&Ing=pt\&nrm=iso. Acesso em: 16 set. 2020.

QUEIROZ, C. A dimensão da pandemia. Revista Pesquisa Fapesp, São Paulo, n. 292, 27 maio 2020. Disponível em: https://revistapesquisa.fapesp.br/ wp-content/uploads/2020/05/030-035_covid_notifica\%C3\%A7\%C3\%A3o_292.pdf. Acesso em: 29 out. 2020.

REIS, A. P. dos et al. Informação sobre gênero, raça/etnia e posição social para o controle da pandemia de Covid-19 no Brasil. Nota técnica $n^{\circ}$ 07/2020. Salvador: Rede CoVida, 2020. Disponível em: https://redecovida.org/relatorios/informacaosobre-genero-raca-etnia-e-posicao-social-para-o-controle-da-pandemia-decovid-19-no-brasil/. Acesso em: 22 out. 2020.

ROSSETTO, E. V.; LUNA, E. J. de A. Relacionamento entre bases de dados para vigilância da pandemia de influenza A(H1N1)pdm09, Brasil, 2009-2010. Caderno de Saúde Pública, Rio de Janeiro, v. 32, n. 7., 2016. DOI: https://doi. org/10.1590/0102-311X00014115. Disponível em: http://www.scielo.br/scielo. php?script=sci_arttext\&pid=S0102-311X2016000705002\&lng=en\&nrm=iso. Acesso em: 29 out. 2020.

SALVADOR. Secretaria Municipal de Saúde. Doença pelo Novo Coronavírus (Covid19). Boletim Epidemiológico, Salvador, n. 24, p. 1-7, 3 out. 2020. Disponível em: http://www.cievs.saude.salvador.ba.gov.br/download/boletim-24_2020-smscievs-ssa-covid-19/?wpdmdl=3287\& refresh=5f9330b810eb31603481784.

Acesso em: 22 out.2020.

TEMPORÃO, J. G. O enfrentamento do Brasil diante do risco de uma pandemia de influenza pelo vírus A (H1N1). Epidemiologia e Serviços de Saúde, Brasília, DF, v. 18, n. 3, p. 201-204, set. 2009. DOI: http://dx.doi.org/10.5123/ S1679-49742009000300001. Disponível em http://scielo.iec.gov.br/scielo. php?script=sci_arttext \&pid=S1679-49742009000300001\&lng=pt\&nrm=iso. Acesso em: 29 out. 2020. 
WORLD HEALTH ORGANIZATION-WHO. Interim case reporting form for 2019 Novel Coronavirus (2019-nCoV) of confirmed and probable cases: WHO Minimum Data Set Report Form. 2020. Disponível em: https://www.who.int/ docs/default-source/coronaviruse/20200121-2019-ncov-reporting-form.pdf. Acesso em: 22 out. 2020. 


\section{ANEXOS - Fichas de notificação}

\section{Formulário do e-SUS Notifica-MODELO 25 de agosto de $2020^{14}$}

MINISTÉRIO DA SAÚDE

SECRETARIA DE VIGILÃNCIA EM SAÚdE

Ne

FICHA DE INVESTIGAÇĂO DE SG SUSPEITO DE DOENÇA PELO CORONAVIŔR 2019 - COVID-19 (B34.2)

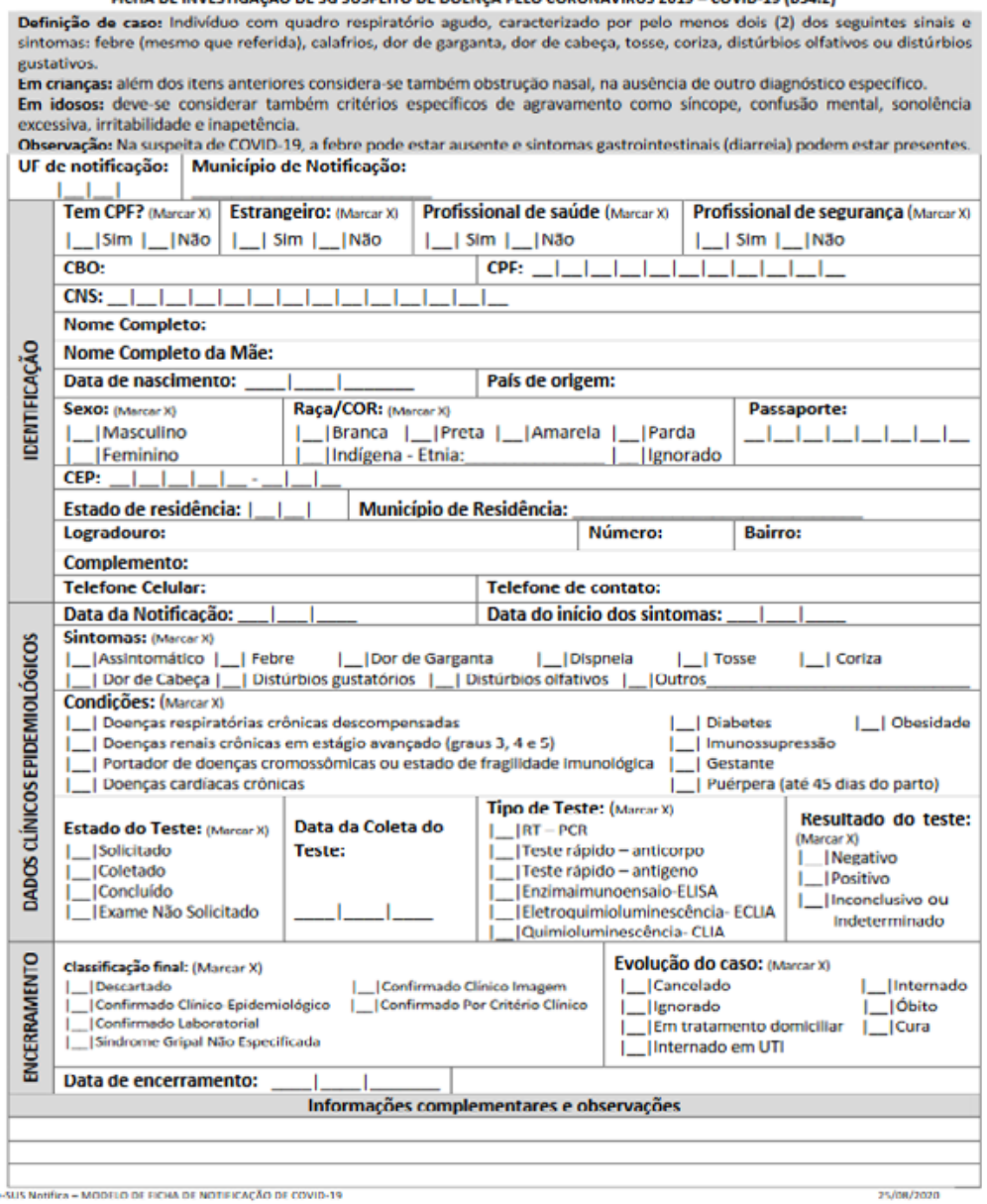

14 Disponível em: https://datasus.saude.gov.br/wp-content/uploads/2020/08/FichaCOVID-19-_25_08_2020.pdf. 


\section{Formulário do Sistema Gerenciador de Ambiente Laboratorial (GAL) ${ }^{15}$}

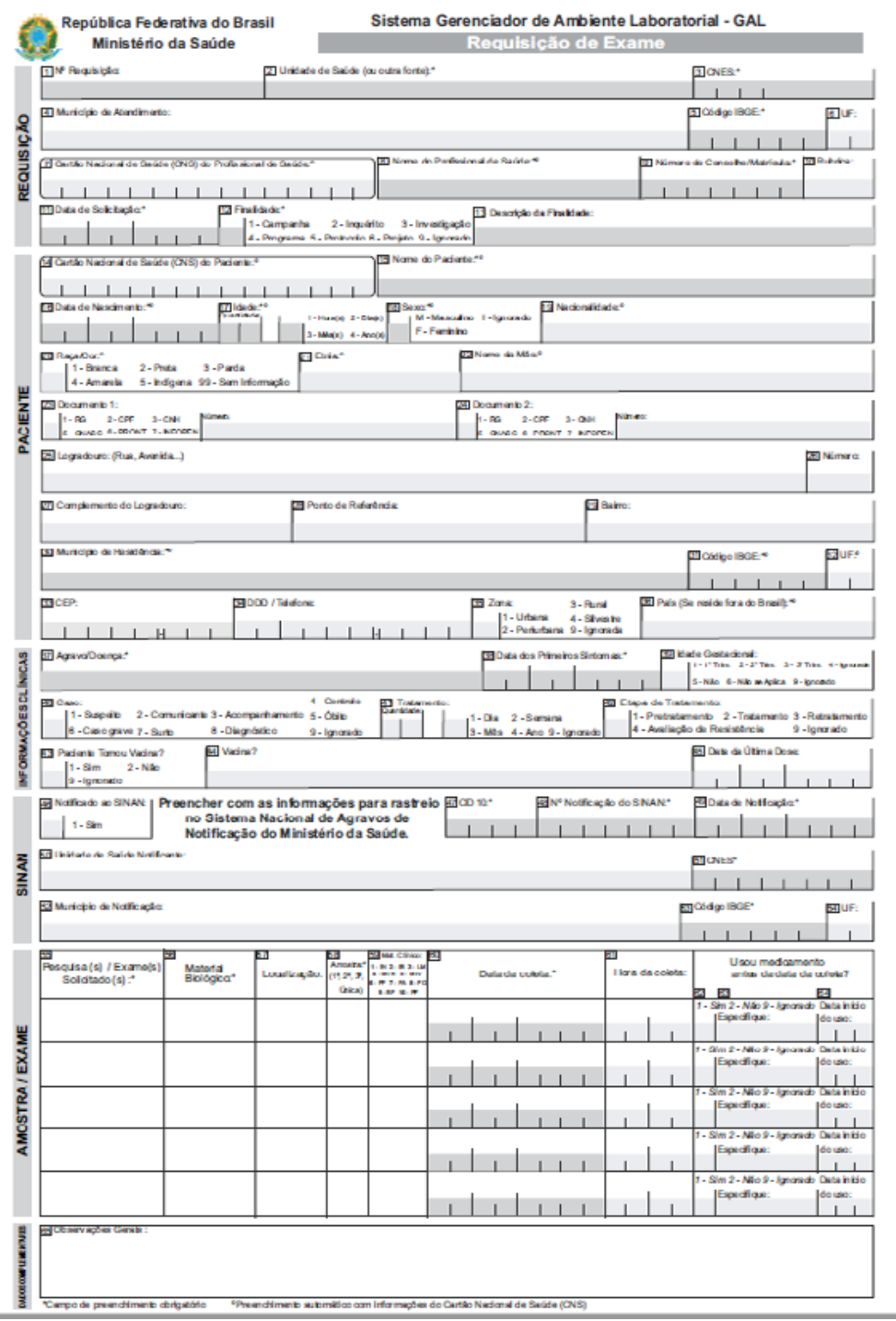

15 Disponível em: https://www.saude.go.gov.br/files/lacen/ficha-do-gal---agravogeral.pdf. 
Formulário de registro individual para casos de SRAG hospitalizados

- MODELO 31 de março de $2020^{16}$

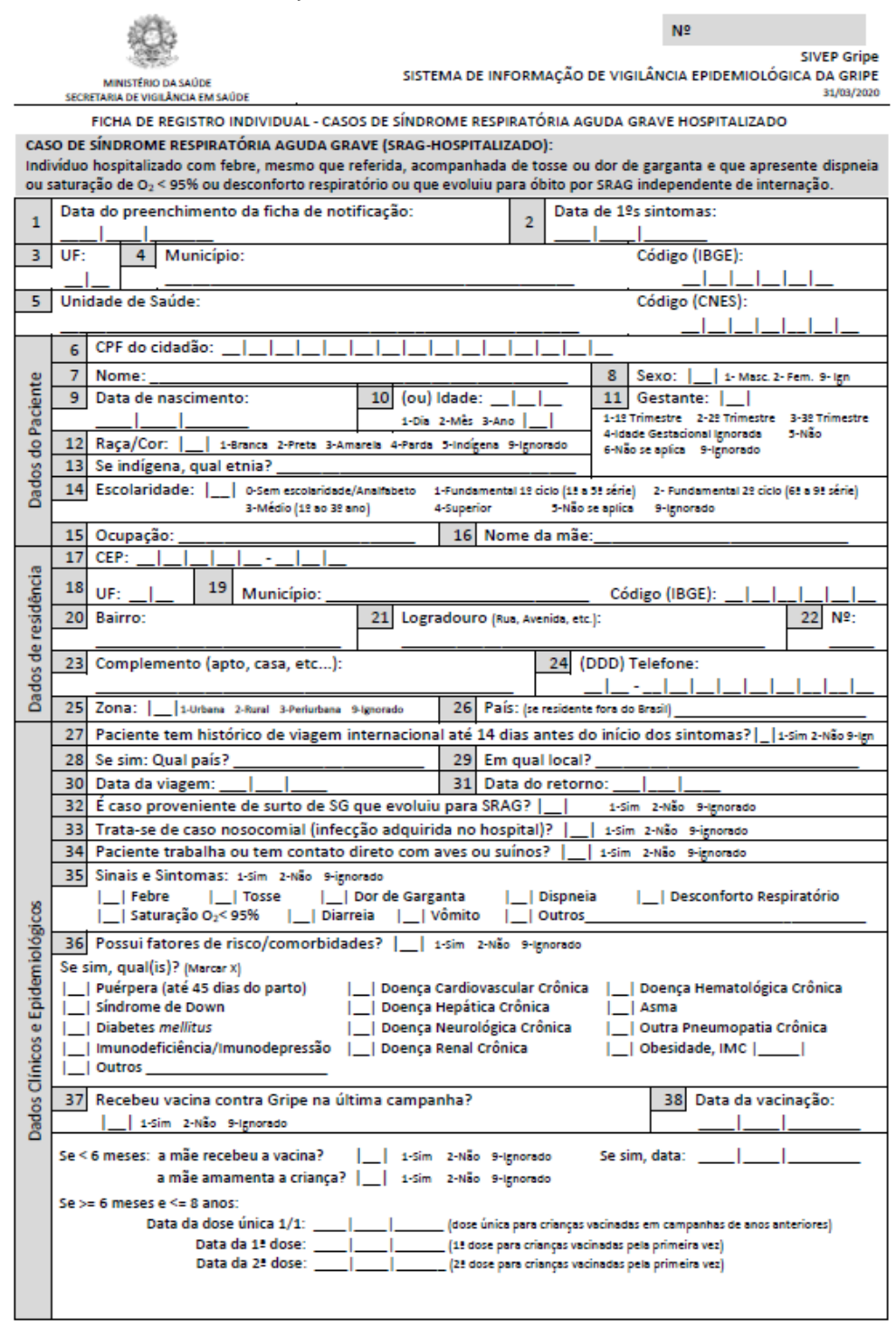

16 Disponível em: http://189.28.128.100/Sivep-Gripe/Ficha_SIVEP_GRIPE_SRAG_ Hospital_31_03_2020.pdf. 


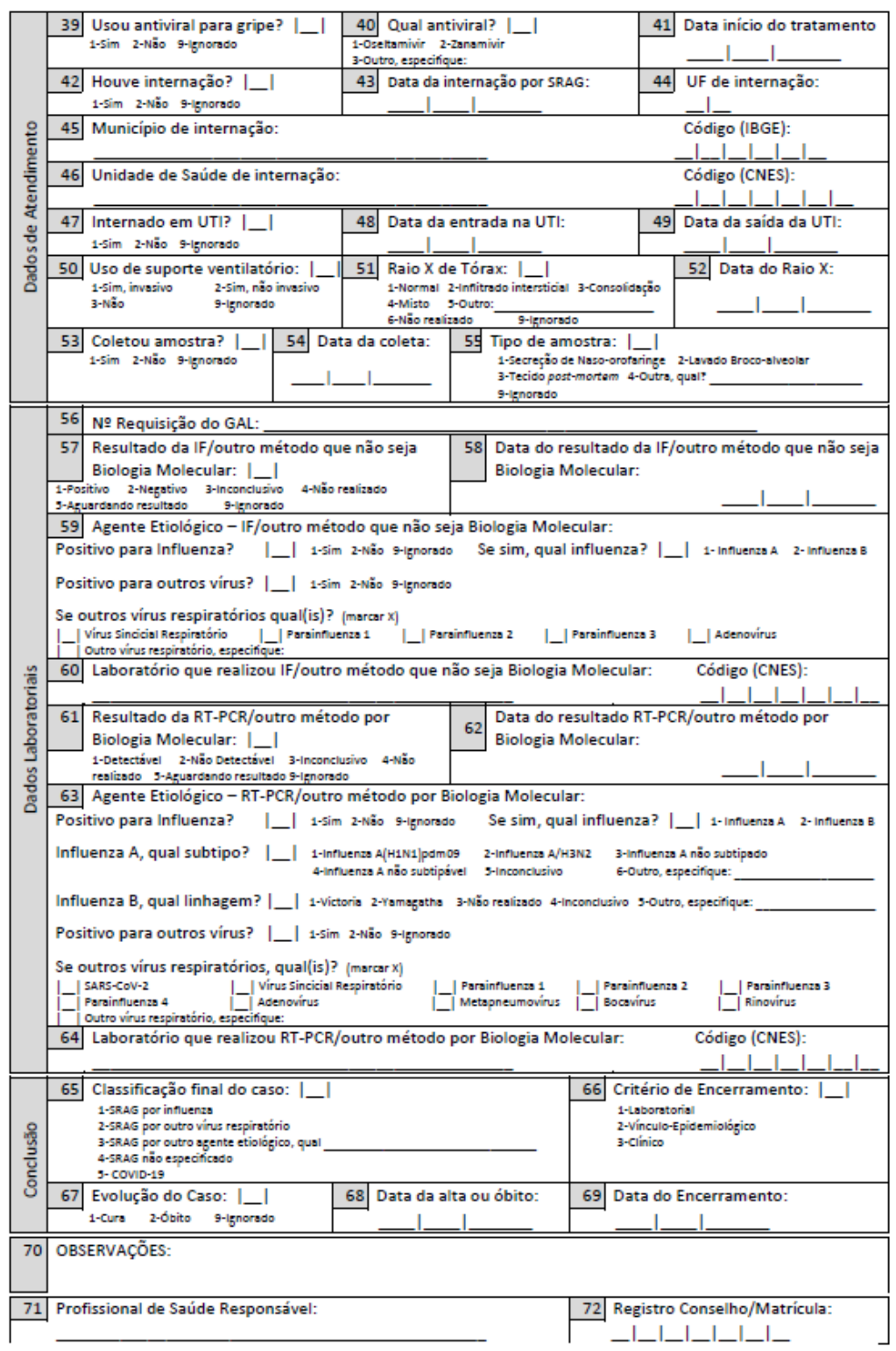

